Supplement of Earth Syst. Dynam., 12, 601-619, 2021

https://doi.org/10.5194/esd-12-601-2021-supplement

(C) Author(s) 2021. CC BY 4.0 License.

(c) (i)

Supplement of

\title{
Interacting tipping elements increase risk of climate domino effects under global warming
}

Nico Wunderling et al.

Correspondence to: Nico Wunderling (nico.wunderling@ pik-potsdam.de)

and Ricarda Winkelmann (ricarda.winkelmann@pik-potsdam.de)

The copyright of individual parts of the supplement might differ from the article licence. 


\begin{tabular}{|c|c|c|}
\hline Parameter group & Parameter & Initial value \\
\hline \multirow{4}{*}{ Critical temperatures $\left.\left({ }^{\circ} \mathrm{C}\right)\right\}$} & $T_{\text {limit, Greenland }}$ & 1.6 \\
\hline & $T_{\text {limit, West Antarctica }}$ & 5.0 \\
\hline & $T_{\text {limit, AMOC }}$ & 5.5 \\
\hline & $T_{\text {limit, Amazon rainforest }}$ & 3.8 \\
\hline \multirow{3}{*}{ Strong links (a.u.) \{} & Greenland $\rightarrow$ AMOC & 0.64 \\
\hline & AMOC $\rightarrow$ Greenland & -0.57 \\
\hline & Greenland $\rightarrow$ West Antarctica & 0.77 \\
\hline \multirow{2}{*}{ Intermediate links (a.u.) } & AMOC $\rightarrow$ Amazon rainforest & 0.0 \\
\hline & West Antarctica $\rightarrow$ AMOC & 0.0 \\
\hline \multirow{2}{*}{ Weak links (a.u.) \{} & West Antarctica $\rightarrow$ Greenland & 0.13 \\
\hline & AMOC $\rightarrow$ West Antarctica & 0.12 \\
\hline
\end{tabular}

Table S 1. Exemplary initial values that have been used to construct the timeseries in Figs. 2 and 3 in the main manuscript. All initial values are random numbers drawn from a uniform distribution with a latin-hypercube sampling algorithm (Baudin, 2013) between their respective limits (see Tabs. 1 and 2). The random numbers for the links have already been multiplied with $1 / 10 \times s_{i j}$ (see Table 2). The exemplary timelines were computed using a network without considering the uncertain links (AMOC $\rightarrow$ Amazon rainforest and West Antarctica $\rightarrow$ AMOC), whose link strengths are set to zero. 

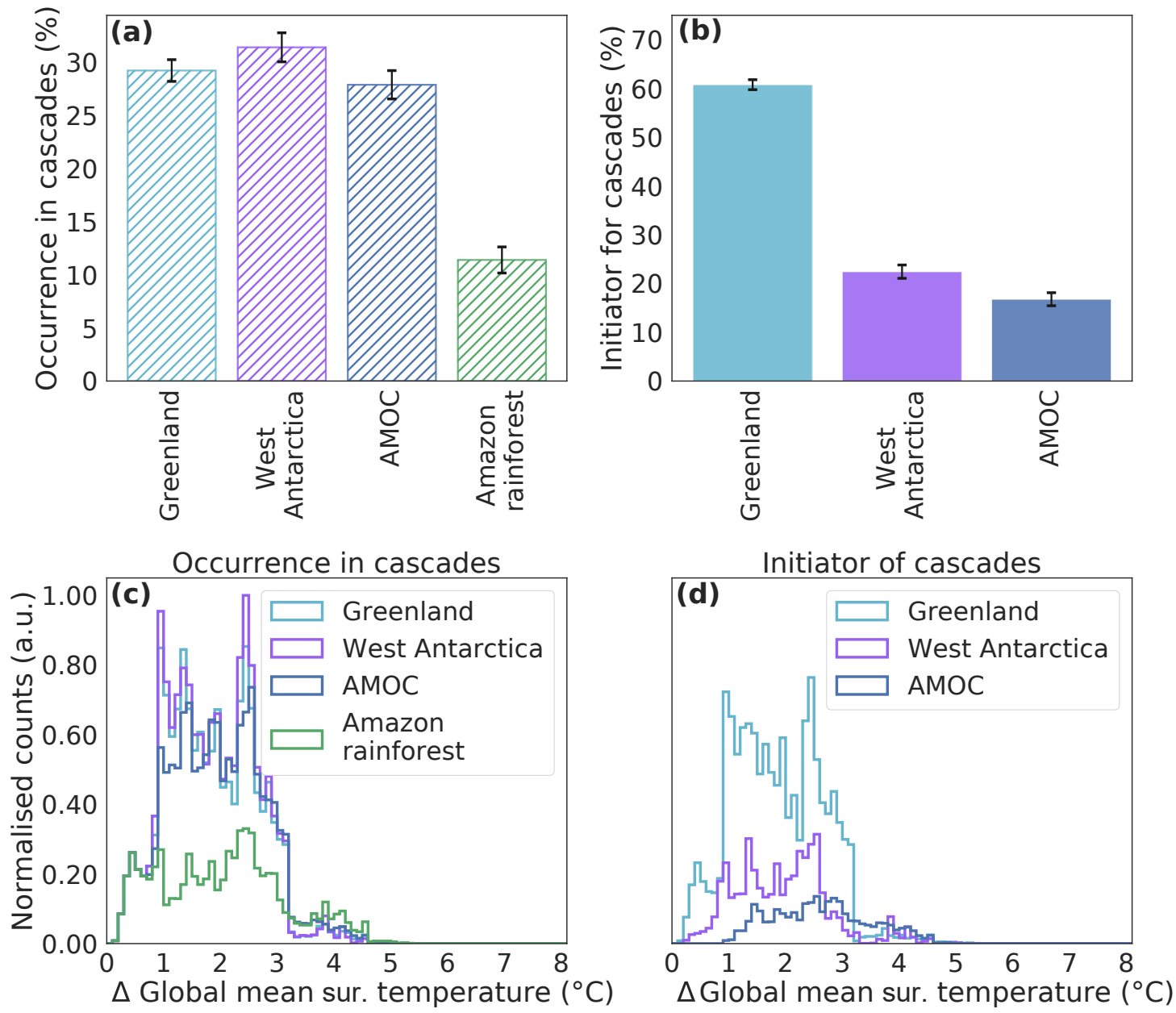

Figure S 1. Role of tipping elements in cascades. (a) Relative frequency in percent of occurrence of a certain tipping element in a tipping cascade (hatched bars). The standard deviation is computed by evaluating the deviation between reasonable network settings (see Sect. 2.7). (b) Relative frequency in percent that a certain tipping element causes a tipping cascade (coloured bars). We define that the cause of a cascade is the element, whose critical temperature is closest to the temperature at which the cascade takes place. Again the error bars show the standard deviation between different network settings as in (a). It must be noted that the Amazon rainforest cannot initiate a tipping cascade since it has no outgoing link (see Fig. 1). (c) Count versus global mean surface temperature increase at which a tipping cascade occurs divided into the respective four tipping elements. (d) Same as in (c), but for the tipping element which causes the cascade. N.B.: (c) and (d) are set to the same scale normalised to the highest value in the histogram. 

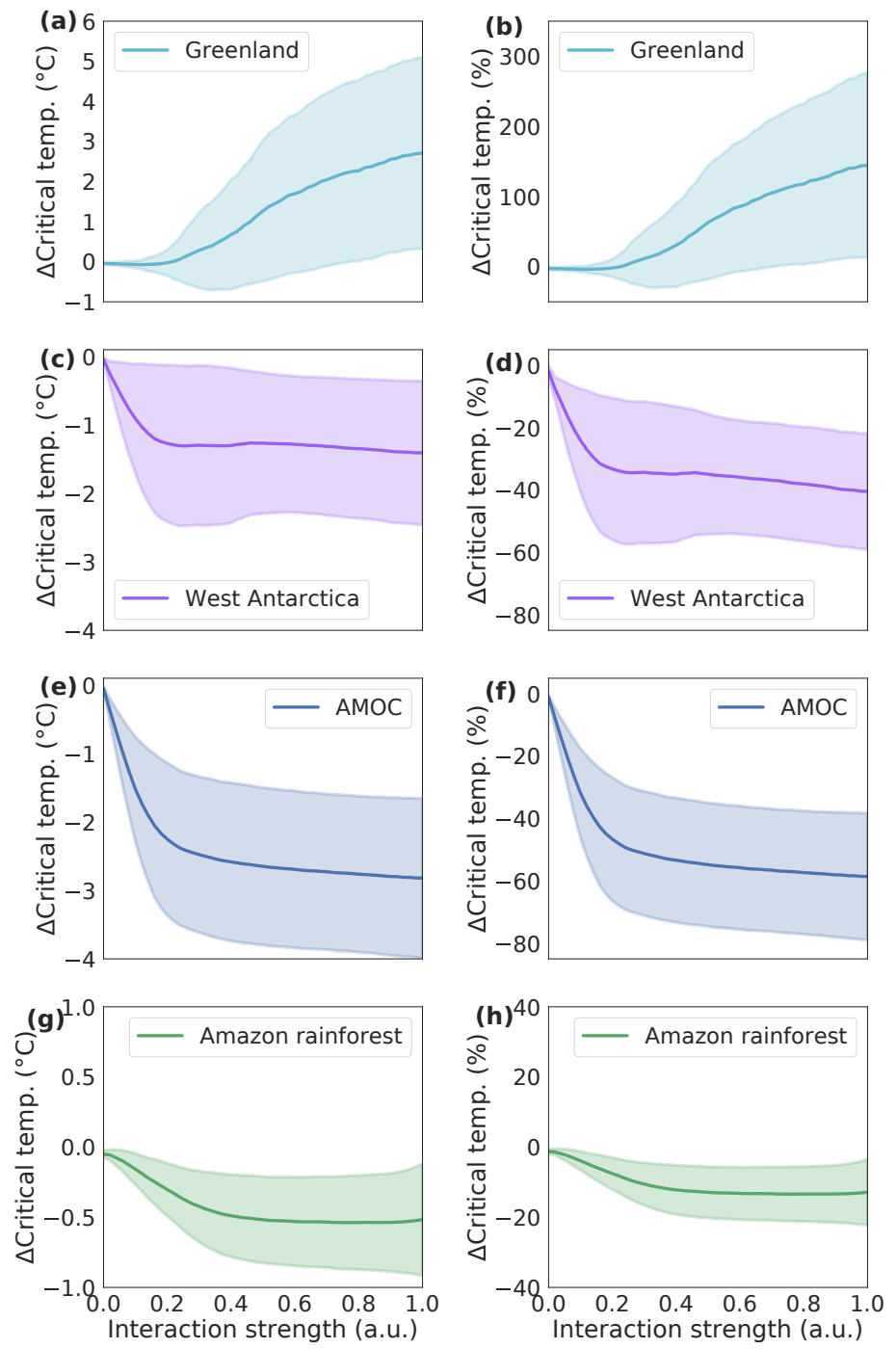

Figure S 2. Difference in critical temperatures with respect to the interaction strength. Difference of critical temperatures in ${ }^{\circ} \mathrm{C}$ (left panels) and \% (right panels) compared to the respective initially drawn critical temperature for the four investigated tipping elements: (a, b) Greenland Ice Sheet, $(\mathbf{c}, \mathbf{d})$ West Antarctic Ice Sheet, $(\mathbf{e}, \mathbf{f})$ AMOC and $(\mathbf{g}, \mathbf{h})$ Amazon rainforest. The standard deviation from the ensemble members is shown as respective colour shading. 


\section{Structural sensitivity analysis including ENSO}

In this section, we perform a structural sensitivity analysis by taking ENSO into account as a tipping element since it is debated whether and to which extent ENSO should be seen as a tipping element (discussion see main manuscript in Sect. 3.4). Below and in Tab. 2, we elaborate on additional references regarding the interactions that include ENSO, equal to the other interactions

5 in the main manuscript (see Sect. 2.2).

1. AMOC $\rightarrow$ ENSO: There are two contradicting impacts representing the influence of the AMOC on ENSO: (I) Oceanic Kelvin waves could start from a colder north Atlantic and travel towards the south. In western Africa, Rossby waves could then be produced travelling in northern and southern direction, which are then converted back into Kelvin waves that move into the Pacific sea. This would intensify the Pacific thermocline and thereby dampen the amplitude of ENSO (Timmermann et al., 2005). (II) When the AMOC becomes weaker, the northern tropical Atlantic would become cooler and northerly trade winds would be strengthened over the northeastern tropical Pacific. It has been suggested that this could lead to a southward shift of the ITCZ (Zhang \& Delworth , 2005). Simultaneously, it is argued that Rossby waves are sent into the northeast tropical Pacific, which would strengthen ENSO (Dong \& Sutton, 2005). Summarised, it is believed that process (II) is more powerful than process (I). Moreover, it has been found in more complex Earth system models that a weakening of the AMOC indeed reinforces the variability of ENSO (Dekker et al., 2018; Sterl et al., 2008). Therefore, this link is set as destabilising (see Fig. S3).

2. ENSO $\rightarrow$ Amazon rainforest: It has been proposed that droughts due to climate variabilities (such as ENSO) could harm the Amazon rainforest and its integrity (Holmgren et al., 2013, 2006; Malhi \& Wright, 2004). With PlaSim, an Earth system model of intermediate complexity, a permanent El-Niño state would severely threaten major parts of the Amazon basin since the forest might suffer from restricted water access in South America (Duque-Villegas et al., 2019). Therefore, we set this link as destabilising (see Fig. S3).

3. ENSO $\rightarrow$ West Antarctic Ice Sheet: There is evidence for heating oceanic effects from El-Niño in the Amundsen and Ross Sea region, while La Niña phases would have the opposite oceanic effect. However, the atmosphere could offset the oceanic effect (Bertler et al., 2006). In addition to that, observations have shown that ice shelves gain height, but lose mass during major El-Niño events in the Amundsen and Ross Sea region (Paolo et al., 2018). In particular, a large surface melt event, that was associated with a strong El-Niño event, took place in 2016 (Nicolas et al., 2017). Still, the interaction between ENSO and West Antarctica is one of the interactions with the highest uncertainty (as also noted in Kriegler et al., 2009). Furthermore, some studies suggest that the frequency of El-Niño events increase with ongoing global warming (Cai et al., 2014). Thus, we set this interaction destabilising (see Tab. S2 and Fig. S3).

4. ENSO $\rightarrow$ AMOC: It has been argued by evaluating reanalysis data that water vapour transport out of the tropical Atlantic is increased (Schmittner et al., 2000). There is contradicting evidence suggesting that El-Niño conditions might or might not have a strengthening impact the deepwater formation in the north Atlantic and with that the strength of the 
AMOC (Spence \& Weaver, 2006; Schmittner et al., 2000). This illustrates that this interaction pair is less well understood than others. Therefore, we consider this link as being of low strength, but with a stabilising (negative) sign since there is only evidence for this direction of interaction (see Fig. S3 and Tab. S2).

5. Amazon rainforest $\rightarrow E N S O$ : The moisture recycling feedback would be stopped in case the Amazon rainforest tips to a large portion (Boers et al., 2017; Zemp et al., 2017; Aragão, 2012). Since it is unknown as to whether this would have an impact on the formation of El-Niño events, this link is set as unclear and its uncertainty is propagated in our Monte Carlo ensemble (see Fig. S3). The strength of this interaction is set very weak due to its possibly very limited impact on ENSO (see Tab. S2).

\begin{tabular}{lcc}
\hline Edge & Maximal link strength $s_{i j}$ (a.u.) & Physical process \\
\hline ENSO $\rightarrow$ Amazon rainforest & +10 & Drying over Amazonia \\
ENSO $\rightarrow$ West Antarctica & +5 & Warming of Ross and Amundsen seas \\
AMOC $\rightarrow$ ENSO & +2 & Cooling of North-East tropical Pacific with thermo- \\
& & cline shoaling and weakening of annual cycle in EEP \\
ENSO $\rightarrow$ AMOC & -2 & Enhanced water vapour transport to Pacifics \\
Amazon rainforest $\rightarrow$ ENSO & \pm 1.5 & Changes in tropical moisture supply \\
\hline
\end{tabular}




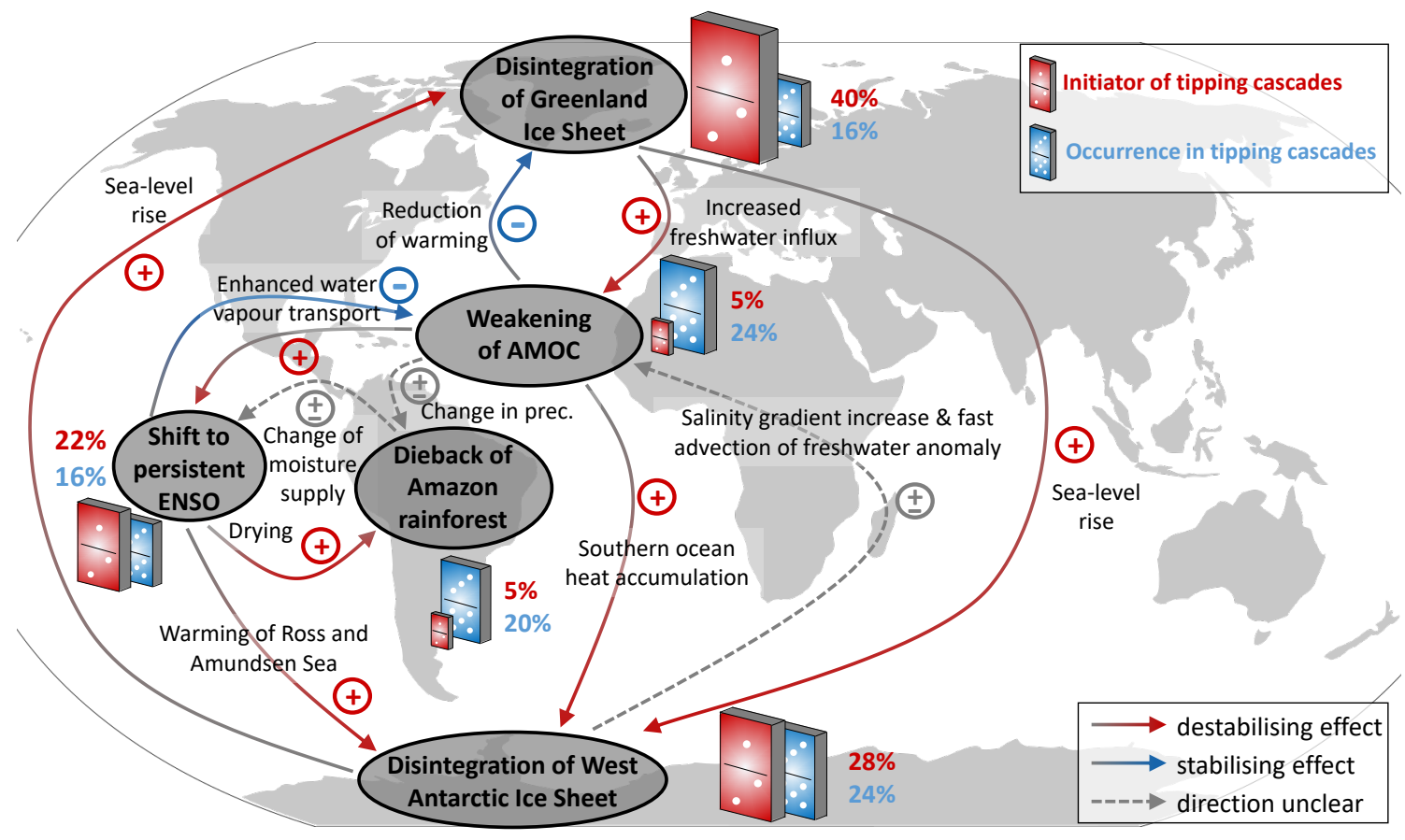

Figure S 3. Interactions between climate tipping elements and their roles in tipping cascades. The Greenland Ice Sheet, West Antarctic Ice Sheet, Atlantic Meridional Overturning Circulation (AMOC), El-Niño Southern Oscillation (ENSO) and the Amazon rainforest are depicted together with their main interaction pathways (Kriegler et al., 2009). Same as in Fig. 1 in the main manuscript, but including ENSO as a tipping element. 

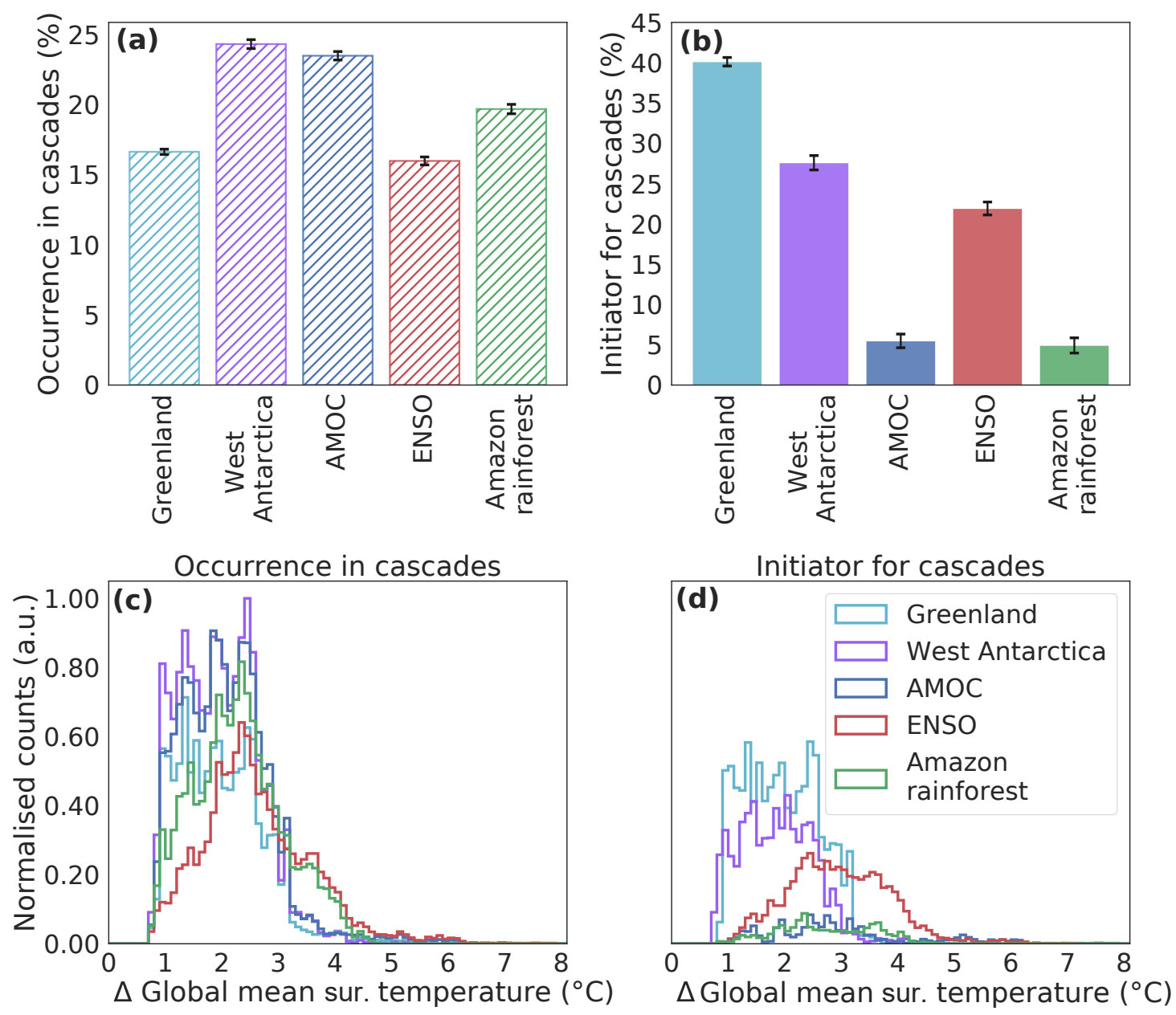

Figure S 4. Role of the tipping elements including ENSO. The panels (a,b) show the same as in Fig. S3, but with error bars (standard deviation). In analogy to the the dominos in Fig. S1 (there without ENSO), the panels (a,b) show the frequency of occurrence in a tipping cascade and the frequency in initiating a tipping cascade. The panels (c,d) depict the increase of the global mean surface temperature, at which this cascade occurred or is initiated. The main pattern of the results remains robust, meaning that the large ice sheets are the initiators of cascades, while the AMOC transmits cascades. The role of ENSO is intermediate since it strongly initiates tipping cascades with the Amazon rainforest, but is apart from that less often (than other tipping elements) part of a tipping cascade and also mediates some cascades. 

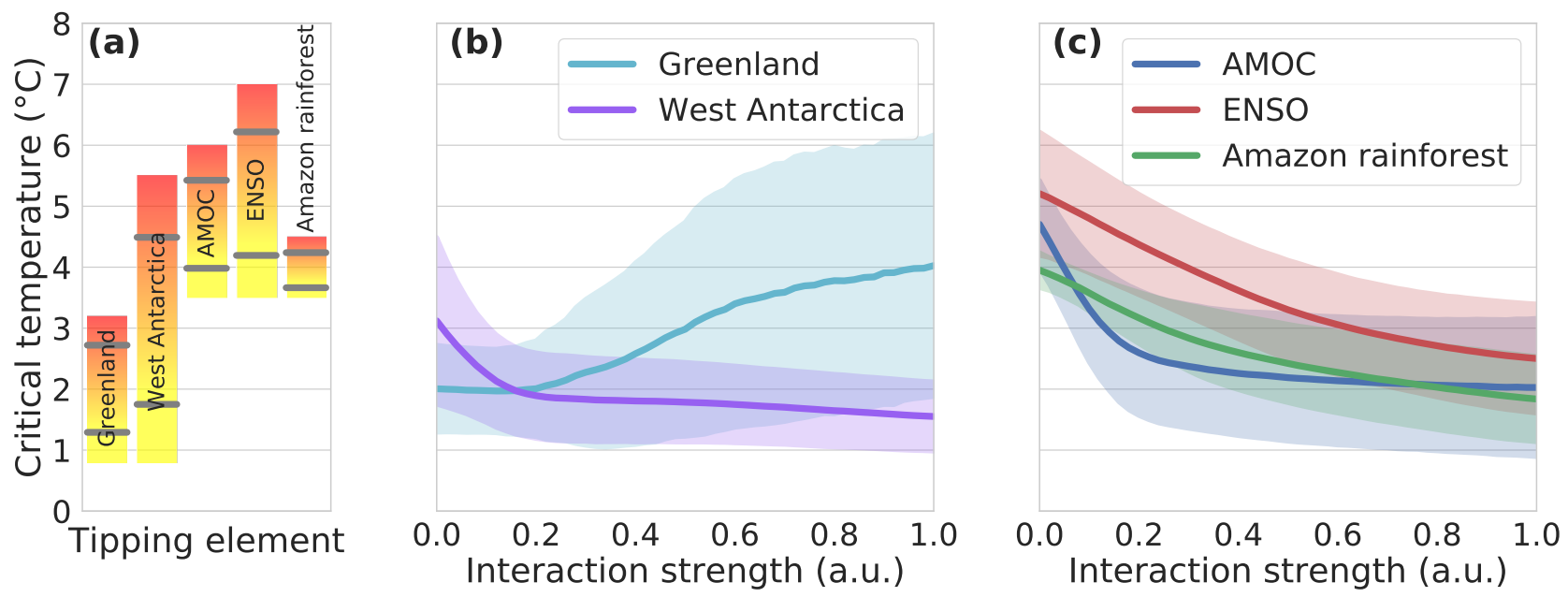

Figure S 5. Shift of critical temperature ranges due to interactions with ENSO. The panels are the same as in Fig. 4 of the main manuscript excluding ENSO. With increasing interaction strength, the critical temperatures develop similar as in the case without ENSO for the Greenland Ice Sheet, the West Antarctic Ice Sheet and the AMOC. For the Amazon rainforest, there is now also a strong reduction of its critical temperature since it is strongly connected and influenced by ENSO. 

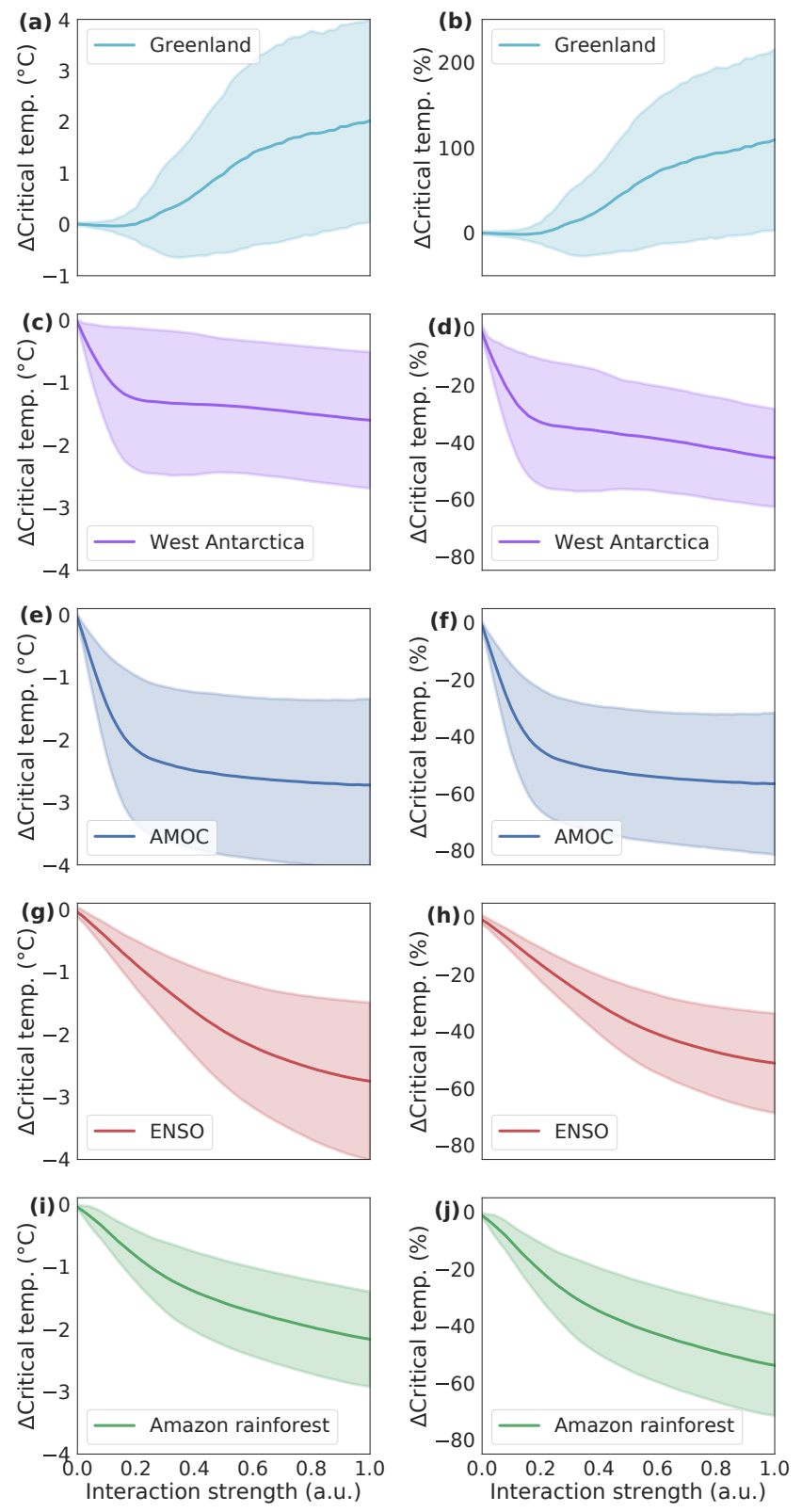

Figure S 6. Difference in critical temperatures with respect to the interaction strength including ENSO. The panels show the same as in Fig. S2 without ENSO. The results are similar apart from the Amazon rainforest that shows more reduction in its critical temperature level due to its strong interaction with ENSO. 


\section{(a)}

(b) 4-element

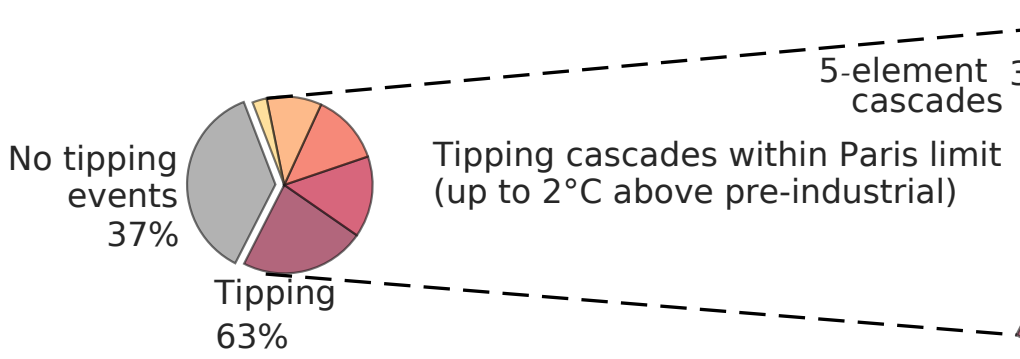
cascades $63 \%$

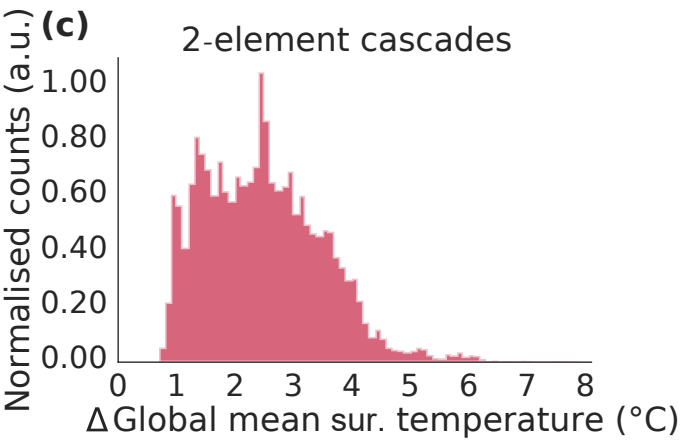

(e) 2-element cascades

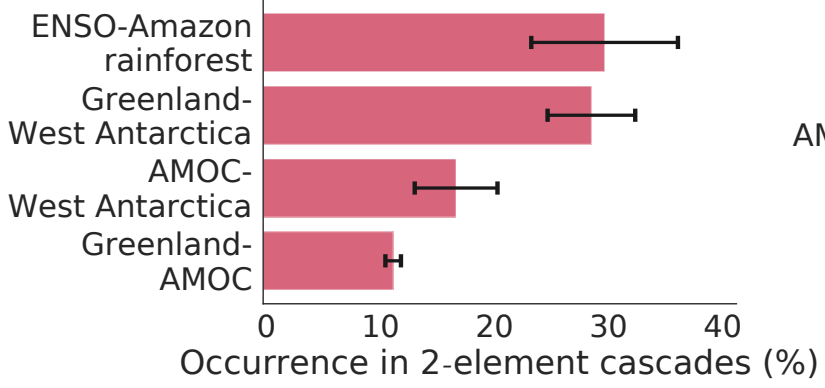

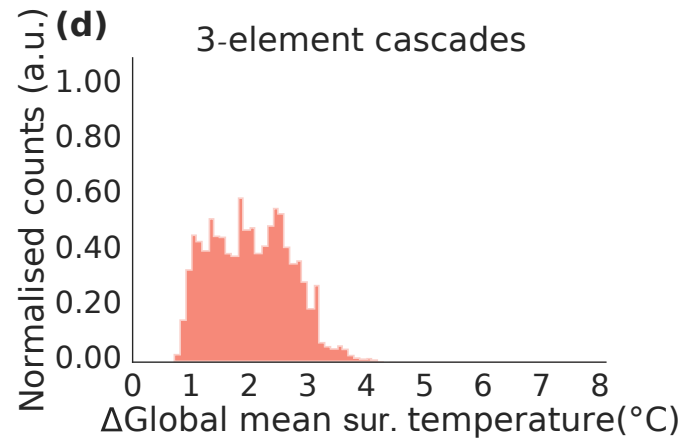

(f) 3-element cascades

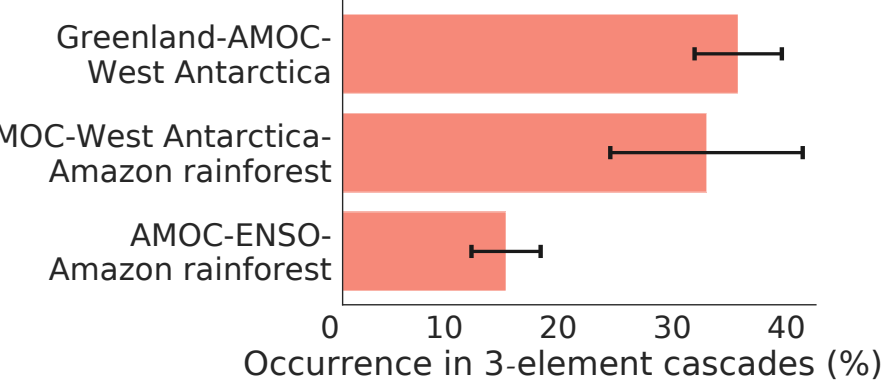

Figure S 7. Tipping cascades with ENSO. The results without ENSO are shown in Fig. 5. The warming levels of tipping cascades are very similar to the simulations that exclude ENSO apart from the fact that tipping cascades including ENSO are now possible. One such prominent tipping cascade includes the Amazon rainforest (see panels (e) and (f)). See Fig. S8 for the distribution of tipping cascades of size four and five expanding the analysis from the panels (c) and (d). 

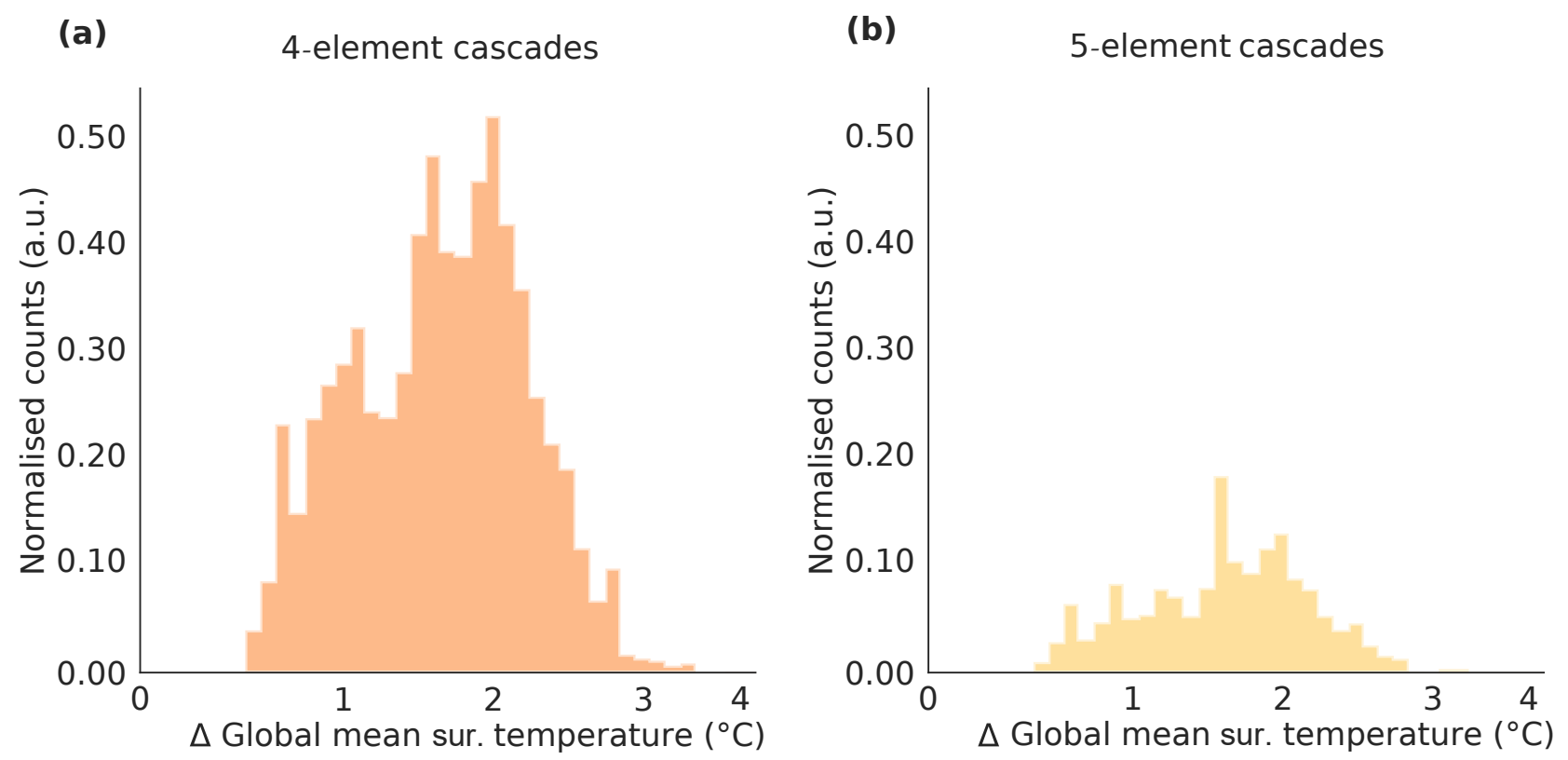

Figure S 8. Tipping cascades of size four and five versus temperature increase. (a) Tipping cascades of size four, (b) Tipping cascades of size five. The scale is the same as in Fig. S7 panels (c) and (d), but here we show a zoom-in in temperature increase and normalised counts to improve visibility. 


\section{References}

Aragão, L.E.: Environmental science: The rainforest's water pump, Nature, 489, 217-218, 2012.

Baudin, M.: pyDOE: The experimental design package for python, sofware available under the BSD license (3-Clause) at https:// pythonhosted.org/pyDOE/index.html, 2013.

Bertler, N.A.N., Naish, T.R., Mayewski, P.A. and Barrett, P.J.: Opposing oceanic and atmospheric ENSO influences on the Ross Sea Region, Antarctica, Adv. Geosci., 6, 83-86, 2006.

Boers, N., Marwan, N., Barbosa, H. and Kurths, J.: A deforestation-induced tipping point for the South American monsoon system, Sci. Rep., 7, 41489, 2017.

Cai, W., Borlace, S., Lengaigne, M., Van Rensch, P., Collins, M., Vecchi, G., Timmermann, A., Santoso, A., McPhaden, M.J., Wu, L., and England, M.H.: Increasing frequency of extreme El Niño events due to greenhouse warming, Nat. Clim. Change, 4, 111-116, 2014.

Dekker, M. M., Heydt, A. S. V. D., and Dijkstra, H. A.: Cascading transitions in the climate system, Earth Syst. Dyn., 9, 1243-1260, 2018.

Dong, B. and Sutton, R.T.: Mechanism of interdecadal thermohaline circulation variability in a coupled ocean-atmosphere GCM, J. Climate, 18, 1117-1135, 2005.

Duque-Villegas, M., Salazar, J.F. and Rendón, A.M.: Tipping the ENSO into a permanent El Niño can trigger state transitions in global terrestrial ecosystems, Earth Syst. Dyn., 10, 2019.

Holmgren, M., Stapp, P., Dickman, C.R., Gracia, C., Graham, S., Gutiérrez, J.R., Hice, C., Jaksic, F., Kelt, D.A., Letnic, M. and Lima, M.: Extreme climatic events shape arid and semiarid ecosystems, Front. Ecol. Environ., 4, 87-95, 2006.

Holmgren, M., Hirota, M., Van Nes, E.H. and Scheffer, M.: Effects of interannual climate variability on tropical tree cover, Nat. Clim. Change, 3, 755-758, 2013.

60 Kriegler, E., Hall, J.W., Held, H., Dawson, R., and Schellnhuber, H. J.: Imprecise probability assessment of tipping points in the climate system, P. Natl. Acad. Sci. USA, 106, 5041-5046, 2009.

Malhi, Y. and Wright, J.: Spatial patterns and recent trends in the climate of tropical rainforest regions, Philos. Trans. R. Soc. B, 359, 311-329, 2004.

Nicolas, J.P., Vogelmann, A.M., Scott, R.C., Wilson, A.B., Cadeddu, M.P., Bromwich, D.H., Verlinde, J., Lubin, D., Russell, L.M., Jenkinson, C. and Powers, H.H.: January 2016 extensive summer melt in West Antarctica favoured by strong El Niño, Nat. Communs, 8, 15799, 2017.

Paolo, F.S., Padman, L., Fricker, H.A., Adusumilli, S., Howard, S. and Siegfried, M.R.: Response of Pacific-sector Antarctic ice shelves to the El-Niño/Southern oscillation, Nat. Geosci, 11, 121-126, 2018.

Schmittner, A., Appenzeller, C. and Stocker, T.F.: Enhanced Atlantic freshwater export during El Niño, Geophys. Res. Lett., 27, 1163-1166, 2000.

Spence, J.P. and Weaver, A.J.: The impact of tropical Atlantic freshwater fluxes on the North Atlantic meridional overturning circulation, J. Climate, 19, 4592-4604, 2006.

Sterl, A., Severijns, C., Dijkstra, H., Hazeleger, W., van Oldenborgh, G.J., van den Broeke, M., Burgers, G., van den Hurk, B., van Leeuwen, P.J. and van Velthoven, P.: When can we expect extremely high surface temperatures?. Geophys. Res. Lett., 35, $14,2008$.

Timmermann, A., An, S.I., Krebs, U. and Goosse, H.: ENSO suppression due to weakening of the North Atlantic thermohaline circulation, J. Climate, 18, 3122-3139, 2005.

Zemp, D.C., Schleussner, C.F., Barbosa, H.M., Hirota, M., Montade, V., Sampaio, G., Staal, A., Wang-Erlandsson, L. and Rammig, A.: Self-amplified Amazon forest loss due to vegetation-atmosphere feedbacks, Nat. Communs., 8, 1-10, 2017. 
Zhang, R. and Delworth, T.L.: Simulated tropical response to a substantial weakening of the Atlantic thermohaline circulation, J. Climate, $18,1853-1860,2005$. 